\title{
ACOUSTIC IMAGING OF SELECTED AREAS OF GDANSK BAY WITH THE AID OF PARAMETRIC ECHOSOUNDER AND SIDE-SCAN SONAR
}

\author{
Grażyna Grelowska ${ }^{2}$ \\ Eugeniusz Kozaczka² \\ Wojciech Szymczak ${ }^{1}$ \\ ${ }^{1}$ Polish Naval Academy, Poland \\ ${ }^{2}$ Gdansk University of Technology, Poland
}

\begin{abstract}
The article presents and analyses the data recorded during sounding of the Gdansk Bay seabed with the aid of a parametric echosounder and a side-scan sonar. The accuracy of seabed structure examination, as a condition for obtaining valuable results, requires correct configuration of echolocation devices and proper calibration of peripheral devices, such as the survey unit geographical position sensor - GPS, the navigation unit, the MRU-Z sensor of pitch, roll and heave, and the sound velocity meter, which deliver the data to the bathymetric measurement system. Parametric seabed profilers deliver two types of data: the envelope, and the detailed echo signal without processing. The envelope is used for data visualisation in the form of online echograms, while the echo signal is stored for further analyses, to be performed using dedicated software or, after relevant conversion, in arbitrary programming environment1. The presented data analysis is illustrated by selected sample images recorded by the parametric echosounder and the side-scan sonar during Gdansk Bay sounding.
\end{abstract}

Keywords: echolocation, acoustic imaging, seabed structure examination

\section{INTRODUCTION}

Although hardly assessible, the deep sea becomes more and more interesting for people. Numerous reasons for this growing interest can be named, starting with the willingness to gain more information about the seabed and its environment ${ }^{2,3,4,5}$ and ending with the sailing safety, especially in relatively shallow water regions. Another possible reason is the historical and archaeological research, frequently related with the search for wrecks of ships or airplanes, or other objects resting on the seabed ${ }^{6,7}$.

The next important aspect of underwater exploration is the search for natural resources the inland access to which is limited and which are available under the seabed. This refers to both inanimate natural resources, such as raw energy materials or polymetallic minerals, and animate resources.
Exploitation of undersea energy resources, especially crude oil and natural gas, carries the danger of leaking of those harmful substances to the seawater ${ }^{8}$. To reduce the threat of appearance of such a situation, the areas surrounding drilling platforms and bore-holes, as well as those in the vicinity of submarine pipelines used for long-distance transport of gas and crude oil, are under continuous monitoring.

Such a wide interest in the research and observation of the underwater space facilitates the development of devices and methods for underwater research ${ }^{9,10,11,12}$. The overwhelming majority of these devices make use of acoustic waves as information carriers.

Generally, we try to systematise the knowledge about the underwater world, which we build by analogy to the perception of the space around us on the Earth's surface, in the form of images. These images can be created as graphical 
presentation of the processed acoustic signals ${ }^{13}$. The article shows the seabed images of selected areas of the Gdansk Bay which were obtained with the aid of devices making use of most recent research methods, including those based on the theory of nonlinear acoustics.

\section{MEASURING SYSTEM}

The rig for sea trials was assembled on the 9-m deck of a small survey vessel s/y Windspeel (Fig.1.). The main measuring instrument was the parametric sub-bottom profiler SES-2000 standard, consisting of two components: the main unit integrating the probing pulse generation system, and the receiving unit with analogue-to-digital signal conversion elements, complemented by a matrix of converters - antenna - mounted on starboard side of the vessel, in a specially prepared holder.

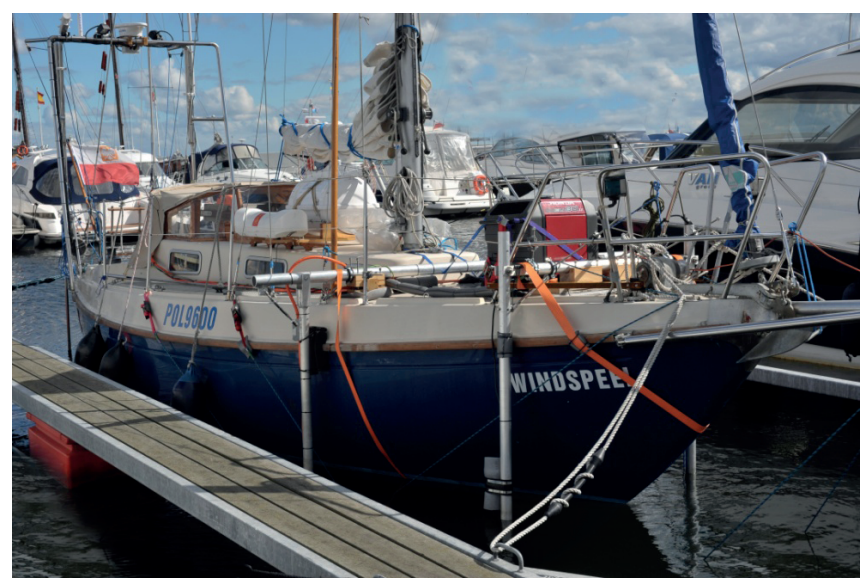

Fig. 1. Survey vessel s/y Windspeel

The profiler emits low-frequency acoustic signals of adjustable time duration. The signal frequency can be set by the user within the range between 4 and $15 \mathrm{kHz}$. Taking into account that the measurements were expected to deliver information on the structure of seabed sediment layers, a relatively long time of signal duration was to be chosen. On the other hand, when searching for objects laying on or buried under the seabed, i.e. in cases when the in-depth resolution is of high importance, short pulses and higher frequencies are to be used. An interesting option, which was used in the research, is the sounding data recording along a set trajectory with the aid of, alternately, two or three different sounding signals. In that case the longitudinal resolution decreases, but the use of two or three different sounding pulses of given frequencies makes it possible to record different data during one survey. The sounding frequencies used during the reported sea trials were equal to $4 \mathrm{kHz}, 8 \mathrm{kHz}$ and $12 \mathrm{kHz}$. Due to the fact that the optimal measuring conditions refer to calm sea, a phenomenon which cannot be controlled by the research worker, the emitted beam is to be controlled to compensate ship's rolls and gain the information on heave in order to eliminate it. The recorded data were stored on the hard disc in two formats: ${ }^{*}$.SES files, which contained the data concerning the signal envelope, and ${ }^{\star}$. RAW files with the complete time-history of the detailed echo signal. The measuring unit was supplied with $230 \mathrm{~V}$ (AC) voltage delivered from the DC-AC converter connected to a set of three $110 \mathrm{Ah}$ gel batteries. During the sea trials, the batteries were charged from solar panels and from the engine driven electric current generator, while during the measurement intervals they were additionally charged from the $230 \mathrm{~V}(\mathrm{AC})$ current generator Honda. Additional seabed insonification was done using the side-scan sonar Simrad Structure Scan. Moreover, such equipment as the MRU-Z sensor of pitch, roll and heave, and the precise GPS with position sensor were installed on the survey ship and calibrated. The signals from the sensors were transmitted to the devices using RS-232 distributors. The research included measurements of sound velocity profiles with the aid of the measuring instrument MIDAS SVX2 produced by Valeport (Fig. 2.).

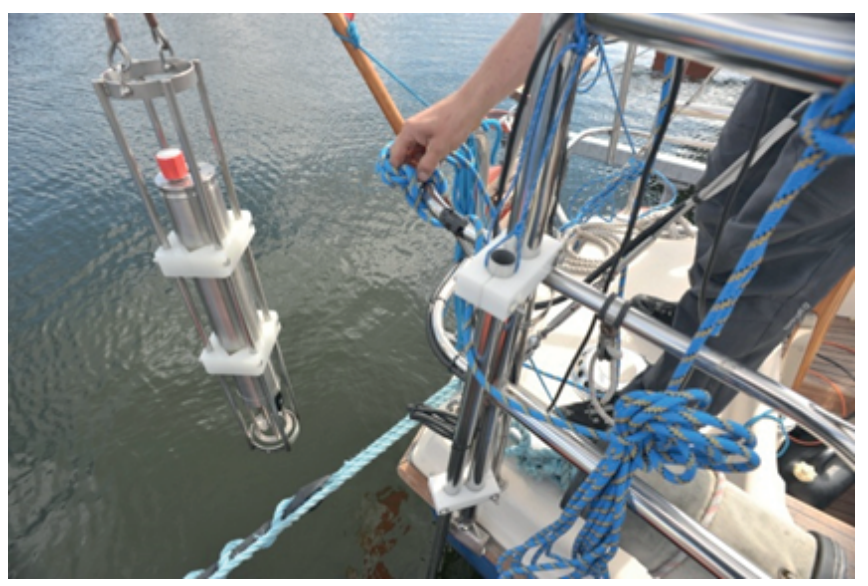

Fig. 2. Sound velocity probe - MIDAS

The collected profiles were immediately entered to the programme controlling the operation of the parametric echosounder. The analysed area and the transects, along which the soundings were planned to be made, were selected based on the geological maps of the Polish Geological Institute. Relevant data were delivered to the navigation software (Nobeltec) connected to the autopilot, which ensured satisfactory accuracy of survey vessel navigation along the set paths.

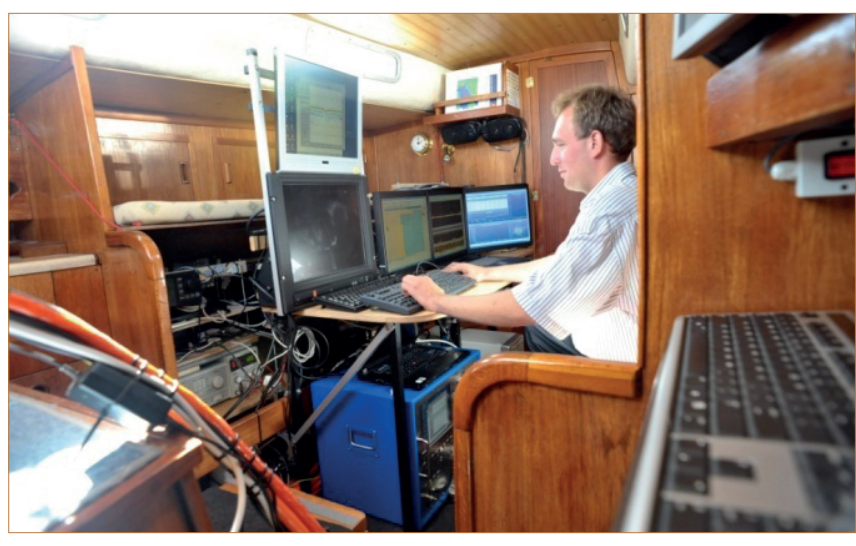

Fig. 3. Operator panel inside the survey vessel 
The operator panel where the recorded data were visualised on monitors, Fig. 3, was assembled inside the survey vessel. Additionally, two screens were installed on the deck to display the navigation chart, the AIS and radar data images (Fig. 4), and the results of parametric echosounder sounding, this way facilitating operator's and steersman's work. Before the beginning of sea measurements, the system was fully calibrated in the harbour, along with checking whether the electrical supply system does not affect negatively the recorded data. This check included correctness of earthing, operation of $\mathrm{DC} / \mathrm{AC}$ converter, etc.

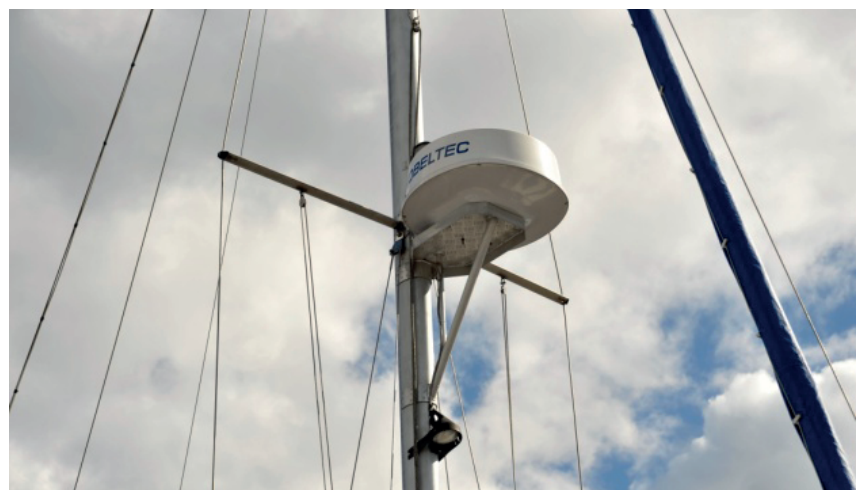

Fig. 4. Navigation device - radar

\section{LABORATORY TESTS}

The laboratory tests, which preceded real in-situ measurements, aimed at, among other aspects, verification of sounding pulses generated by the parametric echosounder transceiver, with further analysis of the effect of changes of individual parameters (pulse duration time - number of generated intervals, frequency, amplification of received signal - TVG) on on-line imaging presented to the operator based on the signal envelope. Another goal of these tests was to determine transmission characteristics for both primary waves, and the frequency difference wave.

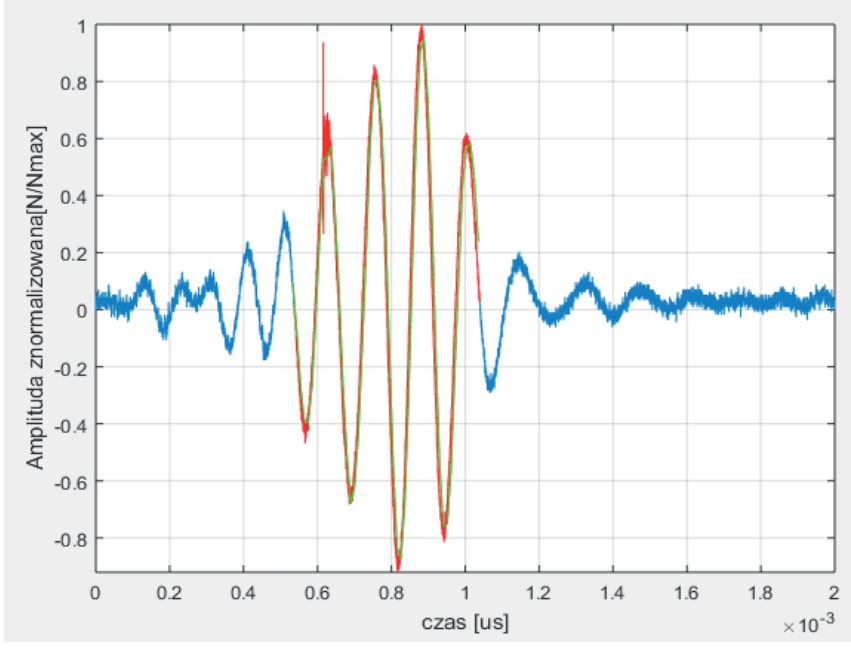

Fig. 5. Sounding pulses: $8 \mathrm{kHz}, 4$ intervals
Because of the properties of parametric wave generation, the main beam of the echosounder was directed horizontally along the largest dimension of the basin. Since the depth and width of the basin were limited, the first important point was proper directing of main lobes of the wave radiating system. A measuring principle was adopted that the antenna was kept in fixed position, while the moving object was the measuring hydrophone. The measuring area was scanned using a precise device made by ISEL, which allowed space scanning with the accuracy of up to $20 \mathrm{um}$.

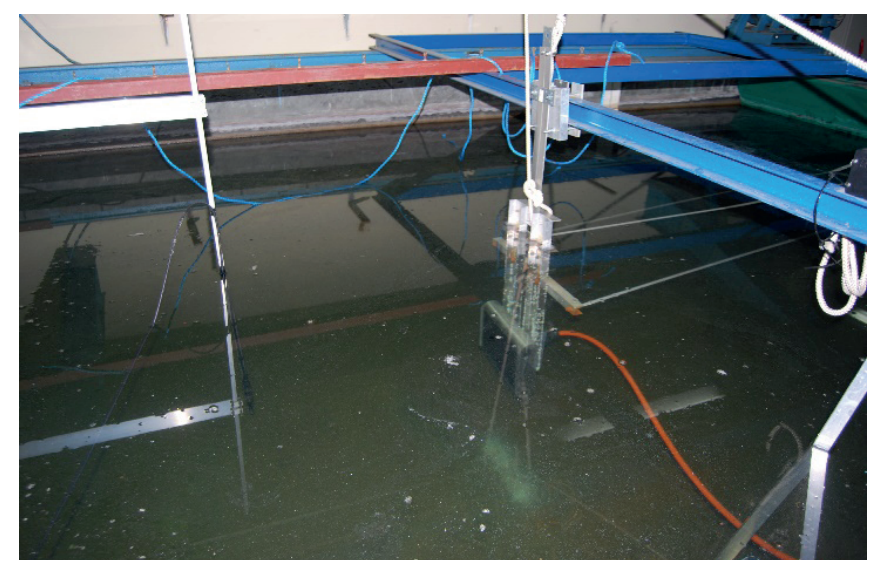

Fig. 6. Parametric echosounder antenna on support

The motion of the hydrophone was controlled using a computer code which enabled precise characteristics to be recorded. The next goal of the tests was to determine acoustic impedances of materials representing typical seabed sediments expected to be found in the water region chosen for in-situ measurements. Figure 7 shows the model of the measuring basin with the drawn directional transmission characteristic.

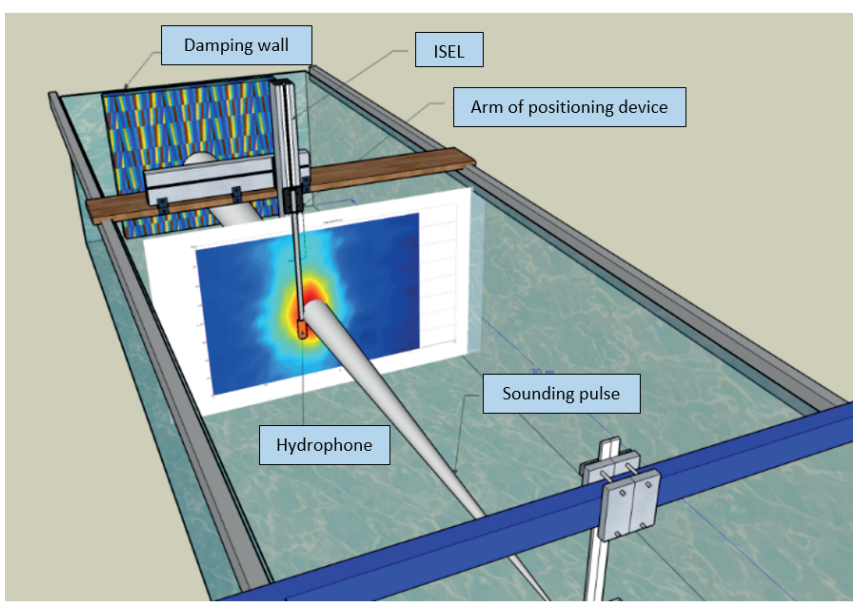

Fig. 7. 3D characteristic of frequency difference wave

According to the theory, the generated pulse of the frequency equal to the frequency difference between primary pulses (in this case, frequencies 100 and $108 \mathrm{kHz}$, for instance) has a similar beam width and no side lobes. 
Figure 8 compares directional characteristics measured in the horizontal plane at a distance of 4 metres from the parametric echosounder transceiver. The red curve represents the primary wave characteristic, while the blue curve - the frequency difference wave. The recorded results confirm similar properties concerning beam width and the absence of side lobes for the pulse whose properties make it possible to penetrate seabed sediments.

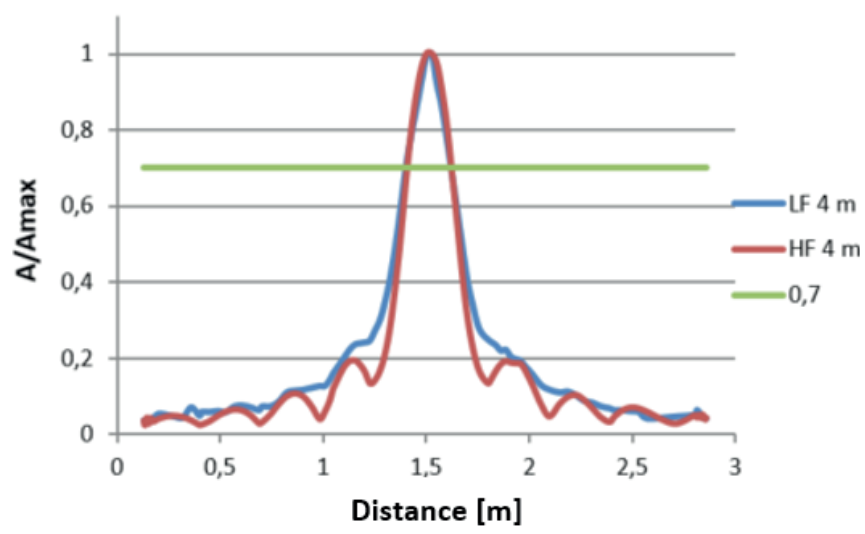

Fig. 8. Horizontal directional characteristic

Specially prepared frames (Fig. 9.), which enabled positioning of seabed sediments taken from selected points of the measuring water region, were used for measuring acoustic impedances of individual materials and assessing the in-depth resolution.

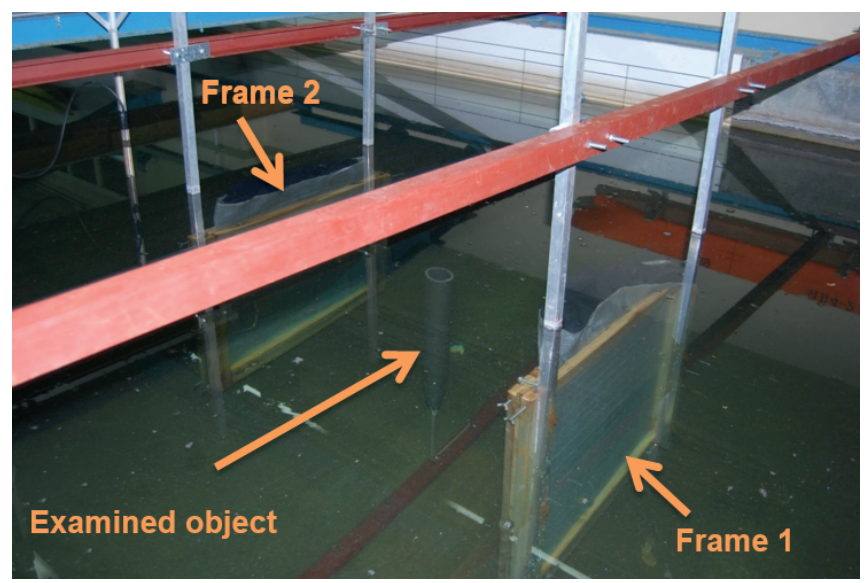

Fig. 9. Frames simulating seabed sediment layers

Figure 10 shows the results of sounding of two frames separated by $1 \mathrm{~m}$ from each other. The tests were performed for the empty space between the frames, and when an object (cylinder made of non-absorbent sponge with air bubbles) was inserted between them. Comparing these two cases revealed very precise and stable object positioning between the two sediment layers.

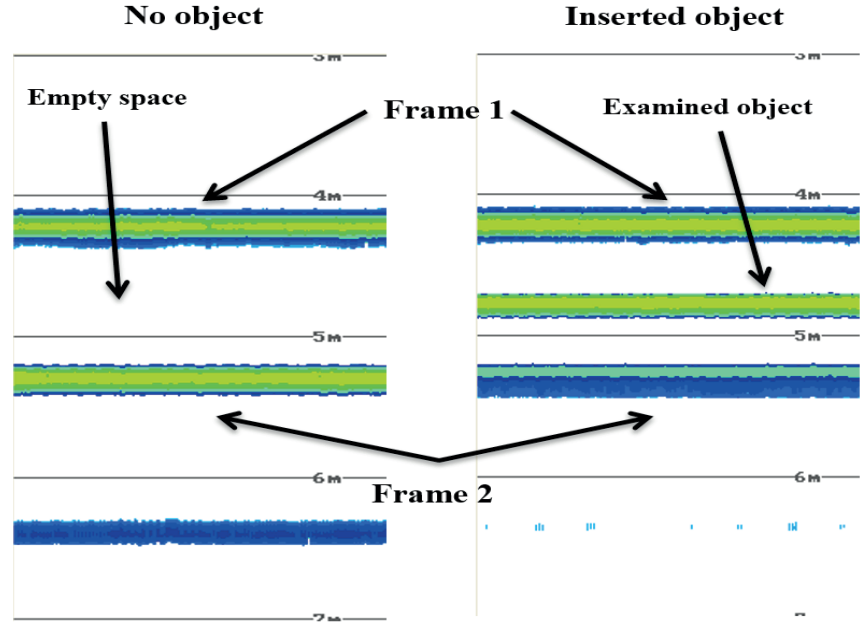

Fig. 10. Result of in-depth resolution test

\section{RESULTS OF IN-SITU MEASUREMENTS}

Two sample results of sounding were selected for presentation as characteristic for sounding in the Gdansk Bay area. The former result is closely related with the geological map developed based on the analysis of the content of sediment samples taken by the Polish Geological Institute using invasive methods ${ }^{14}$. The image of the results collected by the parametric echosounder (Fig. 11.) shows the seabed as a highly reflective surface, and mud sediments in the upper seabed layer. In selected fragments of the echogram, of several kilometres in length, we can observe stratification resulting from the fact that the echo is obtained from the upper mud layer and from the highly reflective sandy bottom situated about $2 \mathrm{~m}$ below. This situation made the sound penetration to deeper seabed layers practically impossible.

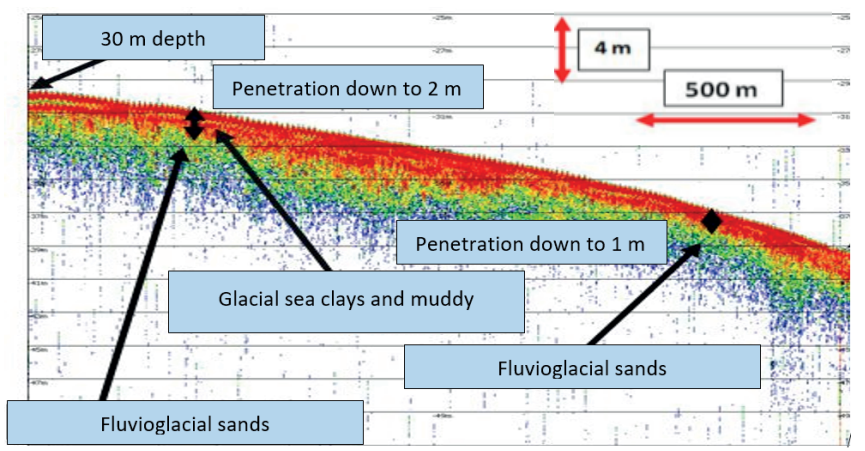

Fig. 11. Sounding: 1-2 $m$ layer of mud and sand

When analysing the second part of sounding (Fig. 12) we can clearly see high stratification resulting from the presence of layers having lower acoustic impedance than that of sand or clay. This allowed deeper penetration into seabed sediment layers. This image is well correlated with the results of the geological research performed by the Polish Geological Institute, from which we can conclude that the 
sediment structure image reaches the layer of boulder clays and glacial sands.

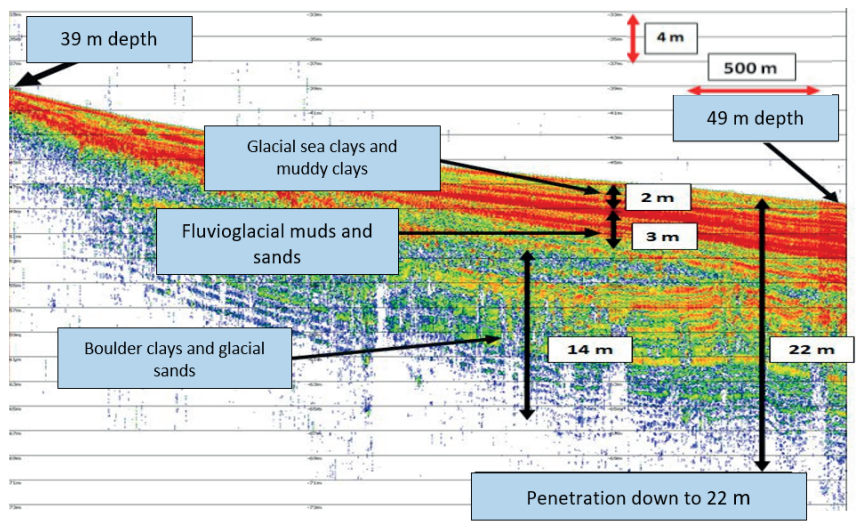

Fig. 12. Muds and clays accumulated under the seabed down to $22 \mathrm{~m}$

When analysing the seabed image recorded with the aid of the side-scan sonar, we can clearly observe changes in the image of the top layer of sediments (Fig. 13.). This is related with two aspects, which are: the acoustic impedance of sediments (decreasing with the increasing depth), and the depth dependent high-frequency attenuation ratio. We should bear in mind, however, that the latter factor is not dominating in the given case. Consecutive layers represent the results of sounding recorded in water regions of increasing depths.

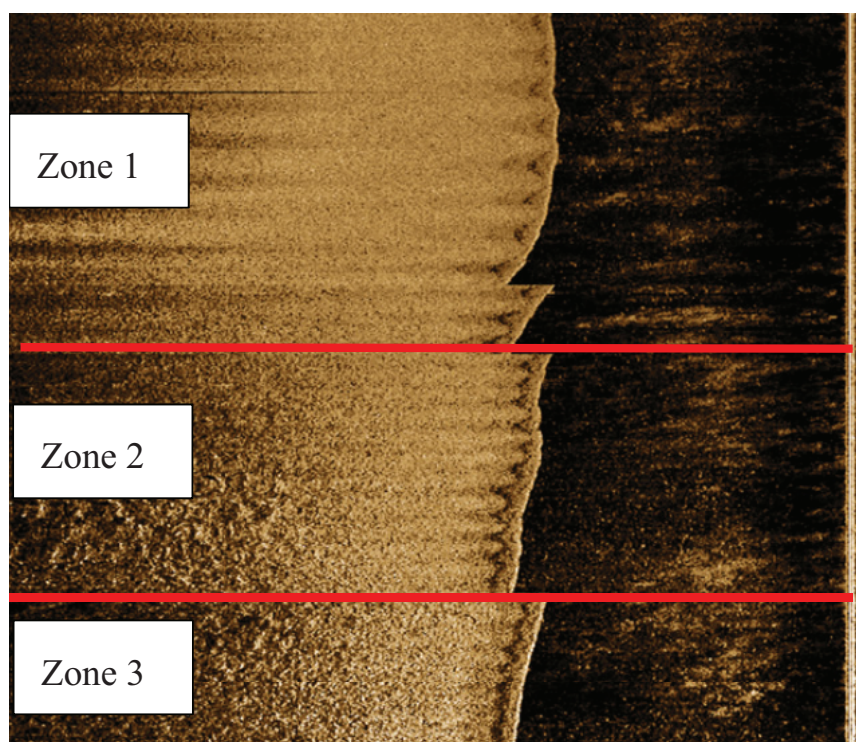

Fig. 13. Sonar image, change in deposit impedance

The image in Fig. 14, Zone 5, shows the results collected at the maximum depth of $49 \mathrm{~m}$.

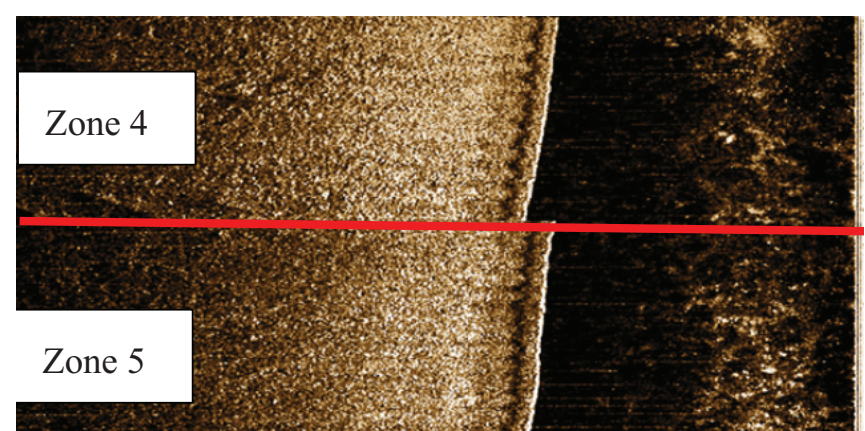

Fig.14. Sonar image, change in deposit impedance

The other selected sample image presents the results recorded at the depth of 10 metres, in the water region situated near the Orlowo cliff. Because of small depth, the image obtained from the side-scan sonar reveals high resolution, which makes it possible to visualise wavy forms created on the sandy sea.

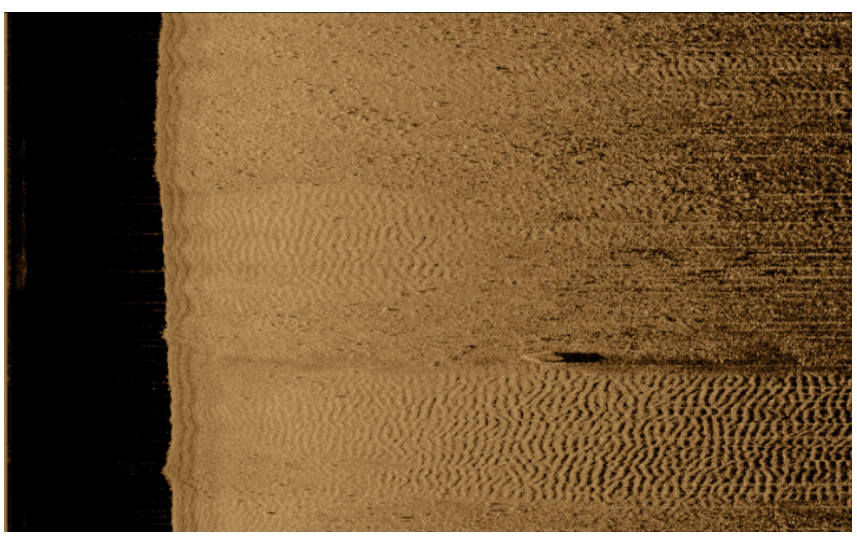

Fig. 15. Clearly visible sandy and wavy seabed

In those conditions (sand - extremely high reflectance) the echosounder image reveals strong reflection from the top layer (Fig. 16.) When the consolidated sandy layer is damaged, (Fig. 16 - zone B), the difference related with the structural seabed change and the resultant sounding pulse scattering is clearly visible.

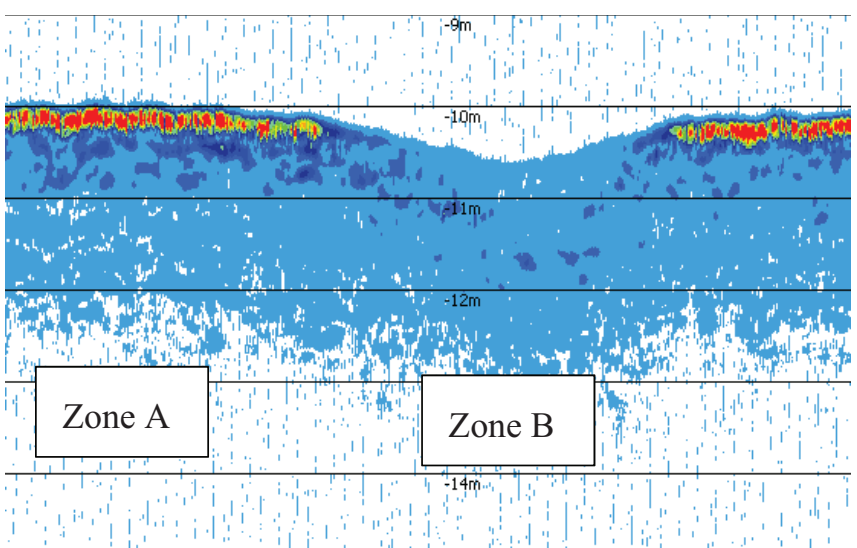

Fig. 16. Image of sandy seabed and excavation 


\section{SUMMARY}

A number of technologies and devices are known which are used for imaging the seabed and the structure of sediments accumulated under its surface. However, obtaining a comprehensive image of the underwater world with the aid of any of these methods is not possible. The article presents two methods for seabed exploration and the analysis of results making use of precise laboratory tests of sounding pulses. Based on the data collected using different devices in the same area, we received different images of the same environment. The presented results confirm that each underwater imaging method delivers only a partial picture, due to limitations resulting from the applied technology. Comprehensive information can only be obtained using a number of complementary techniques. It is noteworthy that parametric echosounders, which belong to the new class of devices working based on the theory of nonlinear acoustics, make it possible to image the structure of sediments and localise objects buried under the seabed, a task which is impossible when using other underwater observation devices.

\section{ACKNOWLEDGEMENTS}

The research was supported in part by the Ministry of Science and Higher Education, within the framework of funds for statutory activities of the Gdansk University of Technology and the Polish Naval Academy.

\section{BIBLIOGRAPHY}

1. E. Kozaczka, G. Grelowska, W. Szymczak, S. Kozaczka, Processing data on sea bottom structure obtained by means of the parametric sounding, Polish Maritime Research, Vol. 19, No 4, 3-10, 2012

2. Peter C. Wille: Sound Images of the Ocean in Research and Monitoring. 2005.

3. L. Hamilton, P. Mulhearn, R. Noecker: Comparison of RoxAnn and QTC-view acoustic bottom classification system performance for the Cairns area, Great Barrier Reef, Australia. Continental Shelf Research 19, 1577 $\div 1597,1999$

4. Leighton T., Mantouka A., White P., Klusek Z., Towards field measurements of populations of methane gas bubbles in marine sediment: an inversion method required for interpreting two-frequency insonification data from sediment containing gas bubbles, Hydroacoustics, 11, 203-224, 2008.

5. G. Grelowska, E. Kozaczka, Underwater acoustic imaging of the sea, Archives of Acoustics, Vol. 39, 4, 439-452, 2014.

6. Kozaczka E., Grelowska G., Kozaczka S., Szymczak W., Detection of Objects Buried in the Sea Bottom with the
Use of Parametric Echosounder, Archives on Acoustics, 38, 1, 99-104, 2013.

7. Wunderlich J., Müller S.: High-resolution sub-bottom profiling using parametric acoustics. International Ocean Systems, 7 (4),6 $\div 11,2003$

8. P. Blondel, A. Caiti: Buried Waste in the Seabed Acoustic Imaging and Bio-Toxicity. University of Bath, UK, 2007

9. Tegowski J., Lobbies Z., Seabed characterization using spectral moments of the echo signal, Acta Acustica united with Acustica, 88, 5, 623-626, 2002.

10. Zacharias M. and Dybedal J., The parametric side-scan sonar instrument and synthetic aperture sonar processing, [in:] Buried waste in the seabed. Acoustic imaging and Bio-toxicity, P. Blondel and A. Caiti [Eds.], Springer 2007.

11. G. Grelowska, S. Kozaczka. W. Szymczak: Some methods of the sea bottom recognition. Hydroacoustics, Vol. 12, $69 \div 76,2009$

12. G. Grelowska, E. Kozaczka, S. Kozaczka, W. Szymczak, Gdansk Bay seabed sounding and classification of its results, Polish Maritime Research No 3 (79) Vol 20, s. 45-50, 2013

13. E. Kozaczka, G. Grelowska, S. Kozaczka: Images of the seabed of the Gulf of Gdansk obtained by means of the parametric sonar. Acta Physics Polonica A, Vol. 118, No $1,91 \div 94,2010$

14. Uścinowicz S., Zachowicz J. (1994), Geological map of the bottom of the Baltic Sea, 8 sheets and pamphlet, scale 1:200 000, Polish Geological Institute, Warsaw. 


\section{CONTACT WITH THE AUTHORS}

\section{Grażyna Grelowska}

e-mail:koe@o2.pl

Gdansk University of Technology

ul. G. Narutowicza 11/12

80-233 Gdansk

Poland

\section{Eugeniusz Kozaczka}

e-mail:koe@o2.pl

Gdansk University of Technology

ul. G. Narutowicza 11/12

80-233 Gdansk

Poland

\section{Wojciech Szymczak}

e-mail:ws2@o2.pl

Polish Naval Academy

ul. Śmidowicza 69

81-127 Gdynia

Poland 